\title{
Low cost Low Visual Aids can improve the life of a section of Human Resource of Society- the facts and fallacies.
}

\author{
Dr Manasi De, Dr Sudipta Dey \\ 1(Associate Professor (WBES)Lady Brabourne College,Kolkata,WB, India) \\ 2(Dr Sudipta Dey, Director, Eye Micro Surgery \&Diagnostic Centre, Kolkata WB, India)
}

\begin{abstract}
Apart from Medical professionals and experts there are a few people in the society who have knowledge about the usefulness of Low Visual Aids. Visually impaired persons are those who suffer from low vision have normally treated as Blind. A Survey was conducted in different blind schools in West Bengal, India to assess the impacts of LVAs on Visually Challenged students of the blind schools who are treated as blind. From the survey it is revealed that a section of blind students, studying in blind schools have some useful residual functional vision to do his / her day-to-day activities which can be improved with Low Visual Aids (LVAs). In this way they can live a life like a normal people. Unfortunately, visually challenged students are still squeezing themselves with the Braille system. The members of administrative bodies, teachers, staffs, guardians of the visually challenged students are either remained ignorant or have little ideas about the advantageous uses of low cost LVAs. Some blind schools show their apathy to use LVAs. S0 a section of the human resource remained unused/under- used condition which is not supportive to the socio- economic development of a country like India. Awareness generation programmes can improve the situation through the involvements of the society for the proper utilization of a section of under used human resource of the country.

This work is a tale of experiences which have gathered through the blind school survey in West Bengal, India.

Key Words: Blind Schools, Human Resource, Low Visual Devices, Society, Visually Challenged Students.
\end{abstract}

\section{Introduction:}

A good number of Visually Challenged students have suffered from low vision which is actually a functional state rather than a numerical expression of visual acuity. Generally visually impaired persons are treated as blind. But they have some useful residual functional vision to do his / her day-to-day activities which can be improved with the Low Visual Aids ( LVAs). About 98 percent people of our society is ignorant about residual functional vision and also the usefulness of the LVAs. As a result the visually challenged are remaining as a burden of their family and the society as a whole.

A survey has been done in three blind schools; two are located at or near the city of the state- Kolkata. These Schools are Ramkrishna Mission Blind Boys Academy, and Light House for the Blind. The third one is Bardhaman Blind School, situated at Barddhaman district. Barddhaman is both agriculturally and industrially developed district in the state of West Bengal in India.

Sample size of the survey is 266

\section{Objectives:}

Objectives of the work are:-

1.1 Identify the barriers of the utilizations of LVAS by the visually challenged students, studying in the blind schools of West Bengal.

1.2 Assess the nature of improvements of life of the visually disabled students by the use of low cost LVAs.

1.3 Assessments of awareness level of the administrative bodies, teaching, non- teaching staffs of the blind schools and also the family members of the students about the usefulness of LVDs.

1.4 Ascertain the role of Government and Non Government Organizations to popularize LVAs into the society.

\section{Methodology:}

2.1 Clinical testing of the students of blind schools to identify that section of the students who have residual functional vision.

2.2 Questionnaire survey of the visually impaired students, their parents, family members, teachers, staffs and administrative members of the blind schools to assess their perception regarding Low Visual Aids.

2.3. Application of quantitative techniques.

2.4 Final analysis of the observation 


\section{Clinical Result of the survey:}

After clinical testing of 193 visually impaired students of Ramkrishna Mission Blind Boys Academy, and Light House for the Blind, it is observed that $42 \%$ students have some residual functional vision. After proper refraction and use of spectacles on them it is revealed that $2 \%$ have got their distance vision $(>6 / 60 \mathrm{Or}$ $20 / 200)$ and $17 \%$ have obtain their near vision ( $>$ N/18). With the applications of LVAs $19 \%$ have improved distance vision ( $>6 / 60$ or $20 / 200)$ and $29 \%$ have improved their near vision $(>\mathrm{N} / 18)$. More than $20 \%$ students overall can improve their vision by Low Visual Devices. It can be said that the vision improvements with the help of LVAs is satisfactory.

Result of the Barddhaman Blind School is less satisfactory than the previous two schools. 23\% students of this school have residual functional vision. After proper refraction and spectacle use none has got their distance vision. But only $6 \%$ have their near vision. With the use of LVAs $3 \%$ have got distance vision and $13 \%$ have near vision. Overall improvement by the LVAs is more than $10 \%$ into the visually disable students in Barddhaman Blind School.

With the help of Low Visual devices these students can see the letters of the news papers, books, deep colours, mobile phones, blackboard, and human faces clearly. They become enthusiastic and started to behave like a normal human being with these devices. As they can live a normal and improved life in future.

\subsection{Achievement of the Survey:}

In spite of the improvements of vision quality of the visually challenged students with the LVAs it is unfortunate that most of the blind school administrations are less interested to open LVA unit in their schools. But Ramkrishna Mission Blinds Boys Academy is an exception. After getting the result of improvements of students from our clinical testing the school has opened a Low Visual unit at regular basis to train their visually challenged students and staffs about the use and handling of the devices. At present about $20 \%$ visually disabled students of this schools are using LVAs regularly and they are studying like normal student. This is the achievement of our survey. Most interesting point is that the visually disable students are started to dreaming about their future after getting the improvements there in the vision quality by the use of LVAs. They are very glad that they can see the face of their mother, colours of sky, flowers etc.

\section{Visually Impaired Students are using different types of LVAs}
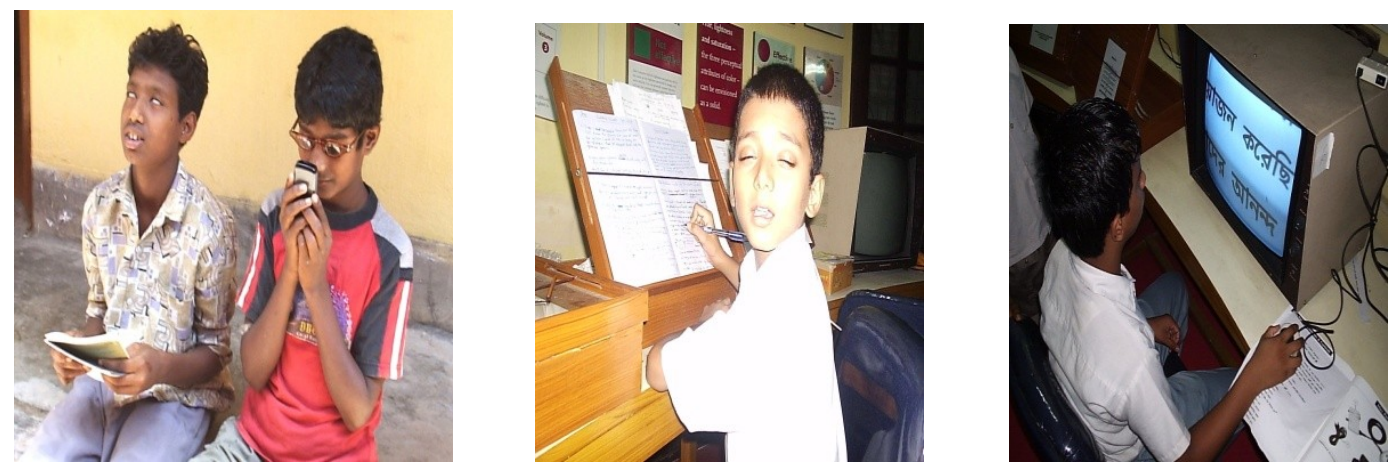

IV. Non Clinical Part:

Only 5\% to $10 \%$ blind children of the society can get admission in the Blind Schools. In the time of questionnaire survey it was observed that $99 \%$ of the visually disabled students' family members, nonteaching staff, about $40 \%$ of the teachers are ignorant about the usefulness of LVAs. One guardian mentioned that he heard about it from the doctor and tried to purchase optical low visual means from a local optical for his son but it was too expensive to him to purchase. In reality many types of LVDs are too cheap to use by all economic classes. Dishonest business men utilize the ignorance of the people, it is unfortunate.

A set of LVAs are distributed free of cost among the visually disabled students to observe the positive impacts and difficulties of its uses. In the time of follow up it is observed that many parents are not allowed their children to use the aids in their school. AS the apparatus improve the sight of his kids, if the devices have been broken down or lost anyway then from where they collect new devices? Most of the parents do not know the central Government supplies these visual aids through the Department of Physically Handicapped, Govt of India , free of cost or at low cost.

So awareness generation about the usefulness of the device is necessary not only for the sake of disabled but also for their family members and sellers of optical devices. 


\subsection{Misuses of Resources: -}

Blind Schools are fortunate enough to get huge funds from different institutions. But most of the blind schools of West Bengal show their apathy to open Low Visual Aids unit and give training to use that apparatus properly to their needful students. As a result a section of visually challenged students are bound to adjust themselves with the Braille system of learning, follow their schools. They also treated as blind. S0 a part of the human resource remained unused/under utilized condition which is not supportive to the socio- economic development of a country.

Awareness generation about this matter is necessary to utilize that section of human resources who are bound to remain outside from the mainstreams of the country. It is unfortunate that no strong governmental and nongovernmental efforts are being observed in this matter. Involvements of mass media, print media NGOs are necessary to reach the common people in the society to make aware about the concept of visual impairments, positive impacts of Low Visual Aids on them.

\section{Conclusion:}

No Blind Census is available in West Bengal /India, from which one can develop an idea about the actual visually disabled population of the state.

Blind school should be renamed as visually impaired or visually challenged school so that there is no use of any negative word like blind.

There must be Low Vision Rehabilitation Centre at each blind school.

Before admission each children should be checked their Vision properly through which maximum utilization of residual functional vision of the disabled students' are possible.

There must be training facilities and supervision on the handling of low visual aids by qualified specialist at regular basis in the schools.

Awareness should be build up into the society by the governmental and non governmental organizations, by the involvement of mass communication department, media, press etc.

\section{Acknowledgement}

Express our gratitude to the Students, Teaching, Non-teaching Staffs, Governing Body of the Blind Schools, surveyed. We shall express our acknowledgement to Mr Anirban Dey for his cooperation to the completion of this work. 